Article

\title{
Regulating Direct-to-Consumer Advertising of Prescription Drugs in the Digital Age
}

\author{
Shannon Gibson \\ Faculty of Law, University of Toronto, 84 Queen's Park, Toronto, Ontario M5S 2C5, Canada; \\ E-Mail: Shannon.Gibson@mail.utoronto.ca; Tel.: +1-416-978-6020
}

Received: 30 April 2014; in revised form: 4 July 2014 / Accepted: 7 July 2014 /

Published: 9 July 2014

\begin{abstract}
The increasing prominence of new Internet and social media technologies and their growing importance as a source of health information are pushing the pharmaceutical industry towards digital channels. This paper explores the potential impacts of the pharmaceutical industry's increasing interest in online marketing and considers how the existing regulatory framework in Canada translates into the social media sphere. Direct-to-consumer advertising (DTCA) of prescription drugs is prohibited in Canada, as it is in most industrialized countries. Although Health Canada has reaffirmed that the existing DTCA regulations apply to new Internet and social media technologies, new dynamics such as user-generated content, consumer propagation, and targeted marketing make applying the existing regulations an uncertain process. Moreover, certain problems often associated with DTCA may be exacerbated in the social media context. Finally, there is skepticism around whether government regulators have the resources or political will to effectively monitor new digital media. As such, this paper considers not only the role of direct government regulation in monitoring and enforcing the regulation of DTCA, but also the role of third party oversight and industry self-regulation - both of which may play an important role in filling the gaps in the regulation of the Internet and social media.
\end{abstract}

Keywords: pharmaceuticals; direct-to-consumer advertising; social media

\section{Introduction}

In recent years, social media sites and new Internet technologies have transformed the way that the world communicates. Companies from all sectors of the economy are scrambling to capitalize on the 
marketing and promotional opportunities offered by this new media. The rise of social media ${ }^{1}$ and other collaborative Internet technologies has created the opportunity for two-way communication where the user can interact directly with websites through user-generated content (UGC), and further, may share content and links through their own social networks. Although the pharmaceutical industry has been slower than many other sectors to invest in social media technologies, this new media is now beginning to transform the way that drug companies interact with consumers. As discussed in the first section of this paper, the increasing prominence of new Internet and social media technologies in modern communication, the growing importance of the Internet as a source health information, and the fiscal realities of prescription drug marketing are all pushing the pharmaceutical industry towards digital channels.

Direct-to-consumer advertising (DTCA) of prescription drugs is prohibited in Canada, as in most industrialized countries; the only two countries that allow such advertising are the US and New Zealand. However, over the past two decades there has been a significant shift in the interpretation of the laws banning DTCA in Canada, which has led to a growing volume of pharmaceutical advertising. Consequently, DTCA has become an increasingly controversial issue in Canada, particularly following a legal challenge brought by CanWest Mediaworks in 2005 which argued that the ban on DTCA violated the section 2(b) right to freedom of expression under the Canadian Charter of Rights and Freedoms [2]. Although this challenge was granted an indefinite adjournment in 2009, the case nonetheless sparked strong debate around DTCA in Canada - a debate, which is far from resolved. While a significant amount of research and literature has been produced in Canada on the issue of DTCA of prescription drugs in general, very little work has been undertaken specifically with regard to the role of social media marketing and emerging Internet technologies_or the resulting policy implications. Therefore, this paper aims to examine the potential impacts of the pharmaceutical industry's increasing interest in online marketing and consider how the existing laws and regulatory framework in Canada translate into the social media sphere.

Proponents of DTCA claim that the ban denies Canadians the right to access health information and that DTCA has the potential to improve health and save lives by encouraging consumers to recognize symptoms and seek medical care at an earlier stage [3]. However, critics contend that DTCA may harm the public by promoting unnecessary and inappropriate use of prescription drugs and that it "fails to provide viewers with a balanced, complete, and accurate appraisal of the range of available treatments and their contribution to therapy" ([3], p. 6). Although the pharmaceutical industry's use of social media is still evolving, some are concerned that many of the problems often associated with DTCA will only be exacerbated in the social media context. For example, in November 2010, four public interest organizations filed a 144-page complaint to the US Federal Trade Commission

1 Defining the scope of social media is often an elusive task since as the technology and its uses evolve, the definition of social media evolves as well. For the purposes of this paper, the discussion of the pharmaceutical industry's use of social media will be focused on what Liang and Mackey refer to as "eDTCA 2.0" which includes social media marketing tools such as Facebook and Twitter, blogs and RSS feeds (Rich Site Summary, also known asreally simple syndication) that provide company-sponsored Web feed communications to users, YouTube channels dedicated to marketing videos, and mobile applications for smartphones, and other mobile technologies [1]. However, while Liang and Mackey focus of branded DTCA, this paper also considers the role of unbranded health information provided by the pharmaceutical industry through the Internet and social media. 
requesting an investigation of what they framed as "unfair and deceptive marketing practices" designed to promote the use of brand name drug products when consumers seek health information online [4]. The complaint cited a number of concerns including " "eavesdropping' on online discussions of health consumers through social media data mining; behavioral tracking to target patients for medical advertising; viral and so called 'word of mouth' techniques; the use of 'unbranded' websites and video channels that redirect patients to sponsored sites... and the presence of 'seemingly independent health bloggers who fail to disclose that they are paid or sponsored by pharmaceutical or other companies"' [5].

Although Health Canada has reaffirmed that the existing DTCA regulations apply to new Internet and social media technologies, regulators are now facing pressure from industry and other stakeholders to provide more detailed guidance on how the existing regulations may be applied in the context of social media. Following a brief overview of the current regulatory framework for DTCA of prescription drugs in Canada, this paper highlights a number of unique features of new Internet technologies that make the application of the existing regulations an uncertain process. In particular, social media introduces new dynamics such as UGC, consumer propagation, and targeted marketing, which are not properly addressed in the existing regulatory framework.

Health Canada is responsible for interpreting and enforcing drug advertising regulations. However, over the past decade, Health Canada has received significant criticism for its failure to adequately enforce the existing rules around DTCA [6]. Given these criticisms, there is likely to be significant skepticism around whether government regulators have the resources or political will to effectively monitor new digital media. As such, the final section of this paper considers not only the role of direct government regulation in monitoring and enforcing the regulation of DTCA on the Internet and social media, but also the role of third party oversight and industry self-regulation - both of which may play an important role in filling the gaps in the regulation of digital channels.

\subsection{The Pharmaceutical Industry's Move towards Online Marketing}

According to many commentators, the pharmaceutical industry is currently in a state of significant flux due to a number of important factors: "[ $\mathrm{t}]$ he meteoric rise of digital information and social-media channels, the still-evolving regulatory environment, the maturing of mainstream blockbuster drugs, and fewer new drugs being brought to market all point to a major inflection point in pharmaceutical marketing" ([7], p. 3). As a result of increasing economic pressures, many pharmaceutical companies are being forced to turn away from traditional — and more expensive-media channels such as print and television, towards more economical "digital channels", namely the Internet and social media platforms [7]. The potential benefits of social media marketing for the pharmaceutical industry are numerous, including "flexibility in marketing blockbuster and niche therapies, ability to reach larger audiences and target specific patients, and better financial analytics of social media and marketing return on investment" [1], not to mention significantly lower costs than traditional forms of advertising. Although investment in Internet and social media advertising remains only a fraction of the total pharmaceutical advertising market, online ad spending by pharmaceutical companies is projected to grow from US\$1.03 billion in 2010 to US\$1.86 billion in 2015 [8]. 
New interactive technologies have become another means through which some pharmaceutical marketers may attempt to create brand preference. Many drug companies are establishing themselves on popular social media platforms such as Facebook, Twitter, and YouTube, and others are integrating new interactive technologies into their standard websites through elements such as videos and interactive features with anatomic images, doctor interviews, and patient testimonials; symptom assessment surveys; doctor discussion guides; and tools to encourage compliance with a prescription [9]. Some of these online tools are aimed at aiding adherence and compliance to a treatment regimen ${ }^{2}$. These sorts of health management tools can be effective in attracting and retaining an audience for the site and, perhaps more importantly, in adding value to a particular brand. Some drug companies are also developing health management tools for mobile applications, which are available in online markets such as the Apple iTunes Store and the Android Market. Although many early smartphone apps focused primarily on diabetes management tools, there has now been rapid expansion into other disease categories [10].

The success of social media marketing campaigns tends to vary depending on the disease category and the target population. In general, marketing campaigns aimed at younger consumers have tended to make better use of social media. Unsurprisingly, according to a 2010 survey in the US, younger consumers were more comfortable than older consumers with seeking and sharing health information via social media [11]. For example, more than $80 \%$ of individuals aged eighteen to twenty-four reported they were likely to share health information through social media and nearly ninety percent said they would trust the information they found through social media [11]. How sensitive consumers feel about publicly discussing a particular health topic ultimately has a significant impact on how willing they are to engage with social media messages related to that topic [9].

\subsection{Patients Go Online for Health Information}

Another significant factor that is pushing pharmaceutical marketers towards digital channels is the fact that consumers are now turning to the Internet as one of their primary sources of health information [12]. Most people turn to the Internet first when looking for health information, even before talking to their doctor, family or friends about a health question [7]. A Statistics Canada survey found that seventy percent of Canadian home-Internet users consulted the web for health information in 2009, up from fifty-nine percent in 2007 [13]. Further, more and more consumers specifically rely on social media as a source of health information. A 2012 survey conducted in the US revealed that "one-third of consumers are using Facebook, Twitter and other social media sites to seek medical information, discuss symptoms and express their opinions about doctors, drugs and health insurers" [11]. Moreover, $34 \%$ of respondents reported that information found through social media would affect their decision about taking a specific medication [11].

2 For example, one brand that has shown particular success in engaging with consumers through customized online health management tools is AstraZeneca's heartburn drug Nexium. Tools on the Nexium website include "the Trigger Checker, a searchable database of acid-reflux trigger ingredients and suggestions for milder substitutes; the Meal Planner, a weekly menu builder with heartburn-preventing recipes; and the Personal Fitness Planner, a tool that creates customized exercise plans designed by a virtual fitness trainer that can be saved on site" ([9], p. 32). 
As more and more consumers turn to the Internet as a primary source of health information, consideration needs to be given to how the health information consumers access online affects their perception of health. On the one hand, patients becoming more involved in their medical care may help improve health outcomes, particularly for chronic illnesses; researching medical concerns on reputable websites can be a positive step for patients if it helps them become more educated about their health [14]. Patients may even be able to accurately diagnose themselves, particularly for common illnesses such as appendicitis and strep throat [14]. On the other hand, many health information sites are unreliable and may mislead patients into thinking they have a medical problem.

As consumers are exposed to more pharmaceutical advertising on the Internet and social media, health professionals need to be conscious of the impact that these messages can have on patient interactions with the health care system [15]. While the debate around the risks and merits of pharmaceutical DTCA is complex and controversial — and beyond the scope of this paper - it is worth noting that various assessments of online drug advertisements have shown that they often make suspect claims and may overemphasize the benefits of the drug [12]. Doctors are increasingly faced with patients who arrive with a self-diagnosis based on information they have found on the Internet. When faced with unexplained symptoms, some consumers may jump to the worst-case scenario conclusion based on the health information they find online - a phenomenon sometimes referred to as "cyberchondria" [12]. DTCA patients encounter online may contribute to this phenomenon by promoting a "perception of vulnerability and illness for which the advertised drug is the solution" and encouraging viewers to consider medical causes for their everyday experiences ([16], p. 101). DTCA may also create a preference among consumers for recently launched drugs over older, established treatments since manufacturers of newer, patented products have a disproportionate opportunity to finance expensive advertising campaigns, "leading the market supply of information to concentrate on newer products to the exclusion of older ones" ([17], para. 35). Moreover, newer drugs tend to be heavily marketed early in the product life cycle when the product may not be adequately assessed for safety $[18]^{3}$.

\section{Regulating DTCA in the Digital Age}

Although all advertisements in Canada are subject to regulations that prohibit false and misleading messages, DTCA for prescription drugs is subject to additional restrictions due to the unique safety concerns connected to these products. First of all, prescription drugs are different from other consumer goods in that they frequently require the expert knowledge of a trained physician in order to be used

A well-publicized example of this problem is the case of the infamous drug Vioxx, which was withdrawn from the market in 2004 after a clinical trial revealed that long-term use of this pain medication was associated with a nearly doubled risk of heart attack or stroke [19]. Although Vioxx had never been proven to be more effective than older, cheaper alternatives, an aggressive DTCA campaign for Vioxx-Merck spent more than US\$500 million dollars advertising Vioxx during its five years on the market, which generated sales of more than US\$2.5 billion [3] — led to the drug being prescribed to a very large number of people soon after its launch, and ultimately, to a correspondingly higher number of adverse drug events [20]. Consequently, the Vioxx crisis stands as a stark reminder that the use of new drugs should be approached with caution and, unless new products represent a significant improvement in safety or efficacy over existing products, they should not routinely replace standard treatments until sufficient evidence has been gathered to support their wide scale use. 
properly. Although prescription drugs are administered with the goal of benefiting the health of the patient, they also have the potential to cause undesirable and even severe side effects. Therefore, doctors must take into account a wide range of individualized factors when making the decision to prescribe a particular drug to a patient.

In Canada, only two types of DTCA for prescription drugs are permitted: (1) reminder ads, which include only the brand name of the drug without any reference to health claims or hints about the product's use, such as listing of medical specialties; and (2) disease-oriented or help-seeking ads, which do not mention a specific brand but discuss a health condition and suggest viewers ask their doctor about an unspecified treatment [3]. Full product ads, such as those commonly seen in the US, which include the brand name of the drug and health claims and risk information, are currently banned under the Canadian regulations [3].

The primary source of regulation on DTCA is the Food and Drugs Act and accompanying regulations. In addition, Health Canada has issued a number of guidance documents to help interpret the content of the legislation. To be considered as DTCA, an advertisement must be directed at consumers and, for reminder ads, must specifically identify a prescription drug product authorized for sale in Canada. Further, the advertisement must be intended for Canadian media; advertisements appearing in foreign media are not subject to Canadian regulatory requirements [21].

\subsection{Food and Drugs Act and Regulations}

In Canada, DTCA of prescription drugs is prohibited under two provisions of the federal Food and Drugs Act, which was first enacted in 1953 as a component of the federal Criminal Code. The Act prohibits DTCA in two main ways. First, the Act places a broad prohibition on advertising prescription-only drugs to the public [3] (i.e., drugs containing medicinal ingredients listed in the Prescription Drug List maintained by Health Canada [22]). Secondly, Section 3(1) and Schedule A of the Act set out a number of diseases and disorders for which "treatments, preventatives or cures" cannot be advertised to the general public [23]. Schedule A includes many diseases such as depression, diabetes, asthma, and heart disease, which are often the subject of pharmaceutical advertising in the US. The rationale for S. 3(1) is the "recognition that people who are seriously ill may be vulnerable to unscrupulous marketing of medicines" ([3], p. 7).

Finally, Section 9 of the Act also places a general prohibition on false and misleading advertising: "No person shall ... advertise any drug in a manner that is false, misleading or deceptive or is likely to create an erroneous impression regarding its character, value, quantity, composition, merit or safety" ([23], s. 9(1)). The law also prohibits DTCA of narcotic drugs (s. 70 of the Narcotic Control Regulations) and controlled drugs (s. G.01.007 of the Food and Drugs Regulations).

From a strict reading of the legislation, it might appear that all forms of advertising of prescription drugs are prohibited in Canada. However, over the last 15 years, there has been a significant shift in the interpretation of the policy governing DTCA of prescription drugs. Despite the apparent ban on DTCA, certain forms of prescription drug advertising are now becoming widespread as a result of amendments and reinterpretation of the legislation [6].

Section 2 of the Act broadly defines advertising as "any representation by any means whatever for the purposes of promoting directly or indirectly the sale or disposal or any food, drug, cosmetic or 
device" ([23], s. 2) — a definition which encompasses both traditional and online media. However, in 1996, Health Canada released a policy statement entitled The Distinction Between Advertising and Other Activities aimed at clarifying the distinction between "advertising" and "information dissemination" [24]. The policy statement suggested that Health Canada was prepared to relax its interpretation of the prohibition against DTCA and gave implicit approval to disease-oriented and help-seeking advertisement for serious diseases. According to Health Canada, these messages are not considered to be "information dissemination" rather than "advertising", a distinction which is based on whether "the primary purpose of the message is to promote the sale of a drug or to provide information" [24]. To qualify as "information dissemination", all information presented must be factual, objective and balanced. In particular, all disease-related statements should use neutral and objective language and must accurately reflect the medical literature; all available treatment options should be treated equally; and a similar type and quality of information on safety and side effects should be presented for all treatment options [24].

In November 2000, another policy statement was released by Health Canada that suggested even further liberalization in the interpretation of the ban on DTCA [25]. It gave explicit approval of help-seeking and reminder advertisements, but reaffirmed that full product ads were illegal. According to the document, reminder ads are deemed to fit within the scope of clause C.01.044, an amendment introduced in 1978 to allow pharmacies to advertise the "brand name, proper name, common name, price and quantity" of a prescription drug for the purpose of competition ([26], s. C.01.044). "Reminder" ads, although deemed by Health Canada to be advertisements, are considered to be within the scope of regulation C.01.044 if they only contain reference to name, price and quantity; however, if a reminder ad is accompanied by messages that allude to its intended use, then the advertisement is considered to be in violation of C.01.044 [6]. This guidance document also clarified that it is prohibited to run two separate ads (i.e., a help-seeking ad and a reminder ad) that taken together would violate the regulations [25].

Note that although Health Canada technically considers help-seeking and disease-oriented ads to be "information dissemination" rather than advertising, for the purposes of the discussion in this paper, help-seeking ads, disease oriented ads and reminder ads are all considered to fall within the scope of DTCA as they are all marketing efforts aimed directly at consumers.

\subsection{Calls for Specific Social Media Guidelines}

During discussions with Health Canada in April 2009, the Pharmaceutical Advertising Advisory Board (PAAB), an independent organization mandated by Health Canada to review pharmaceutical

advertising, outlined the issue of social media marketing and raised the idea of Health Canada creating guidelines for the pharmaceutical industry's use of social media. However, Health Canada declined to issue any such specific guidance [27]. At subsequent meetings between Health Canada and the advertising preclearance agencies in 2010 and 2011, Health Canada once again confirmed they are not currently developing guidance documents for social media advertising [28]. Rather, Health Canada reiterated that existing regulatory advertising provisions apply indiscriminately to all media. They also noted that they have provided guidance on the use of social media to various stakeholders, and participated in the PAAB's 2009 workshops on Social Media Marketing [28]. However, Health 
Canada stated that they would consider adding statements in guidance documents to inform stakeholders that advertising provisions apply to all media and would provide input when PAAB revises its Code of Advertising Acceptance to reflect social media [28].

\subsubsection{Social Media Guidance in the US}

The debate over whether or not government regulators should issue specific guidelines to address the social media context has also arisen in the US. In November 2009, the Food and Drug Administration (FDA) held hearings to learn about the unique challenges of marketing pharmaceutical products via social media and the Internet [15]. Following these hearings, the FDA made a number of public announcements about its intention to develop social media guidance, even placing an item called "Promotion of Prescription Drug Products Using Social Media Tools" on its 2010 agenda [29]. The FDA finally released its first social media guidance in December 2011 [30]. However, social media was only a side topic of the guidance, which was in fact about responding to requests for off-label information and only touched on certain aspects of social media within that discussion. According to Cooke, "[a]11 mention and discussion of a grand, all-encompassing social media guidance has disappeared" and it is highly unlikely that a major statement on the use of social media as a whole will be on the FDA's agenda again anytime soon [31]. As such, pharmaceutical marketers in the US have scaled back their expectations on social media guidance from the FDA.

Although the FDA appears to have moved away from its original intention to issue context-specific guidelines, the fact that social media and Internet technologies are now included in the discussion of regulated communications is, nonetheless, a major step [31]. Some industry analysts now speculate that the inclusion of social media in the off-label marketing guidance is an indication that the FDA will be including discussions of social media in future guidance documents. Indeed, in October 2011, an FDA spokeswoman reported that "[p]olicy and guidance development for promotion of FDA-regulated medical products using the internet and social media tools are among our highest priorities" and that the FDA is currently in the process of developing multiple draft guidances that touch on these issues ([7], p. 11).

\subsubsection{The Challenges of Issuing Specific Social Media Guidance}

Considering the experiences of pharmaceutical regulators in the US and statements made by Health Canada during past meetings with the advertising preclearance agencies, it appears unlikely that Health Canada will issue specific social media guidance in the foreseeable future. To date, Health Canada has not yet included discussion of social media in any guidance document. Instead, it has been the preclearance agencies (discussed in more detail below), rather than Health Canada, that have stepped up in terms of offering industry guidance on how to conduct social media marketing campaigns within Health Canada's regulatory restrictions. In the fall of 2011, Advertising Standards Canada (ASC) updated its guidance materials to include tips for social media marketing in an effort to "help advertisers ensure compliance with the Food and Drugs Act and Regulations when creating direct-to-consumer prescription drug messaging" [32]. These guidance materials include the DTCA Rx Checklist, which helps advertisers to comply with S. C.01.044 of the regulations under the Food and 
Drugs Act, and the DTCI Guide, which helps advertisers to meet the criteria set out in the Health Canada guidance document The Distinction between Advertising and Other Activities.

Overall, the rapidly changing nature of social media and new Internet technologies creates significant concerns that comprehensive guidelines would be complex to design and would require frequent updating - and might ultimately create more confusion than clarity. For example, in January 2012, a spokeswoman from the Association of the British Pharmaceutical Industry stated that "[w]ith the rapid pace of change in digital media, if we had bowed to pressure and produced guidance 12 months ago, this would have been out of date as soon as we'd written it" [33].

Moreover, it is important to consider the potential impact that issuing specific social media guidance may have on the volume of online DTCA. The reluctance of some pharmaceutical companies to fully embrace social media likely arises at least in part from a lack of guidance from regulators on acceptable use of social media technologies to promote pharmaceutical products [15]. As noted by Greene and Kesselheim, "[a]s communications media have evolved, manufacturers have tended to wait for [regulatory authorities] to establish explicit codes of acceptable marketing practices before devoting substantial resources to a new medium" ([15], p. 2087). Consequently, they argue that issuing detailed social media guidance, rather than restricting social marketing, might actually lead to a flood of new online marketing [15]. As such, regulators should be mindful that issuing more detailed social media guidance may lead to a wave of online DTCA and to an attendant need to more closely monitor this complex medium.

\section{The New Dynamics of DTCA in Social Media}

The interactive nature of social media has changed the way that the world communicates. New Internet technologies have not only increased the amount and quality of online information and the speed with which it can be accessed, but have also introduced new modes of interaction. For the purposes of pharmaceutical marketing, there are three primary aspects of social media that have changed the rules of the game: the ability of users to generate their own content; the ability of users to propagate content through their own social networks; and the unprecedented ability of promoters to target advertising based on information contained in user profiles and search history. Further, pharmaceutical marketers are also discovering that consumers are more likely to engage with "unbranded" messages on social media, rather than campaigns around particular brands. As will be discussed in the following sections, each of these aspects of social media introduces complications that make the application of the existing regulations an uncertain process and highlights the need for more regulatory guidance from Health Canada on certain matters.

\subsection{User-Generated Content on Industry-Sponsored Platforms}

Social media is unique in that it gives consumers and patients the opportunity to directly interact with and contribute content to sites. UGC complicates DTCA by raising questions about whether and under what conditions a drug company is responsible for the content created by third parties. Social media may cause manufacturers to lose control over their online marketing campaigns [15].

Although Health Canada has not yet released any specific guidelines regarding the rules for UGC, ASC has highlighted that the basic rules still apply: for material to qualify as a disease-oriented or 
help-seeking ad, the information presented must be "non-promotional" and "no element may directly or indirectly promote the sale of a drug" ([11], p. 2). This rule appears to apply regardless of the source of the content. Indeed, the guidance offered by PAAB and the ASC clearly establish that pharmaceutical companies are responsible for monitoring and controlling all content present on their sponsored Internet and social media sites, including content contributed by users and other third parties [21,34]. Effective monitoring and administrative control of all sponsored websites is important since "[o]nce a website is determined to be advertising, the site in its entirety, including any user-generated content, is subject to regulatory control" [35]. For disease-oriented or help-seeking messages, advertisers must keep an eye out for any UGC that might render the message promotional [34]. For example, a post by a patient on an "informational" website that comments on his or her success with a particular drug product could render the site promotional. Similarly, for reminder ads that feature a particular drug product, any UGC that reveals more than simply the name, price, and quantity of the drug could render the message non-adherent to the DTCA regulations [34].

\subsubsection{The Burden of Monitoring and Moderating}

The ASC cautions that drug manufacturers must recognize the inherent challenges of UGC in social media sites that may quickly render disease-oriented or help-seeking messages non-compliant with the Health Canada guidelines [21]. In particular, the Council recommends: the use of the social media platform's administrative controls to manage the level of UGC that may be posted; the proactive and regular monitoring of social media sites to remove UGC that might render the site non-compliant; and the use of disclaimers to alert consumers that content will be monitored and may be removed to maintain compliance [21]. Of particular concern is UGC that makes reference to off-label uses and adverse events, which ASC indicates should be promptly removed from the site [21].

Industry mistrust of emerging Internet and social media technologies likely also reflects a broader fear of loss of control over their brand message as consumers may post negative or even scathing reviews of a drug product [7]. Ad Age Insights reports that in the US, when social media posts do mention specific pharmaceutical marketing campaigns "consumer sentiment tends to be negativewith large doses of ridicule directed at the list of potential side effects" ([7], p. 13). In an effort to control their brand image on social media platforms, drug companies may have to moderate UGC to remove posts about users' negative experiences with a particular drug product, or negative reviews of the company in general.

Due to the importance of effectively monitoring and moderating industry-sponsored messages on social media sites, drug companies are understandably wary of investing in social media platforms that do not offer sufficient administrative controls. As an illustration, in May 2011, Facebook made changes to its policy that now prevent some page owners from being able to have the commenting function disabled [36]. Previously, some page owners, most notably pharmaceutical and financial companies, were able to request that the commenting feature be disabled on their sponsored pages in order to more easily avoid regulatory issues [37]. This change in policy prompted many pharmaceutical firms to quickly discontinue their product and disease-oriented Facebook pages. While it is unclear what prompted Facebook to make this policy change, Eldon speculates that Facebook may 
have been concerned that "too many drug companies were creating and controlling Pages about generic themes" [37].

Interestingly, industry commentators in the US have reported that the primary reason that pharmaceutical companies wish to disable the commenting function on Facebook pages is because of FDA regulations that require them to report any "adverse events" that they become aware of [35]. In Canada, drug manufacturers must also report all serious adverse drug reactions to the Minister of Health within 15 days of receiving or becoming aware of the information, regardless of whether the adverse reaction occurred in Canada or not ([26], s. C.01.017). In a 2011 guidance document, Health Canada indicates that drug manufacturers should screen websites under their management or responsibility for potential adverse reaction case reports [38]. As noted by the ASC, this would include all adverse events revealed through social media sites [21]. Health Canada also identifies minimum criteria for an adverse reaction report: (1) an identifiable reporter (source); (2) an identifiable patient; (3) a suspect product; and (4) an adverse reaction [38]. Although there is still significant uncertainty around what form and amount of information posted on a social media site would trigger the duty to report an adverse drug event, drug companies would likely prefer to sidestep the issue by disabling commenting functions.

For manufacturers that allow user comments on industry-sponsored sites, monitoring UGC for compliance can prove to be a daunting task. For example, in March 2012, Janssen announced the discontinuation of the Facebook page for its European Psoriasis 360 campaign (although the website, Twitter feed, and YouTube channel continue), stating that "we have found ourselves removing a larger and larger proportion of posts, stifling worthwhile discussions" [39]. Janssen reported that in the final three months of the Facebook page, a third of all posts to the page had to be removed, the majority because they mentioned a specific prescription-only drug by name, or talked about the effectiveness of a particular treatment or its side effects [40]. A small minority of posts were disallowed because of the use of offensive language [40].

\subsubsection{Social Media Testimonials}

One danger that arises when pharmaceutical advertising combines with UGC is the potential for consumers to be misled about the source of the information. The Internet often seems to be filled with "people just like us" who face similar health challenges [41]. However, appearances can be deceiving. Pharmaceutical companies often monitor patients' online social media activities in an attempt to target them for advertising. Moreover, "unbranded websites and paid 'independent' health bloggers target people who are looking for the experience of other fellow sufferers" ([41], p. 2). Such use of social media has sparked controversy since it "give[s] drug companies the ability to improve the credibility of their message by packaging promotional material as personal experience and effectively to disguise marketing messages as independent, third party assessments, which are then spread across social networks" [5].

Some drug companies, particularly in US-based marketing, have launched promotional campaigns that try to harness the interactive nature of social media by inviting consumers to share "testimonials" on their experiences with a particular disease or drug product. As an example, in February 2009, AstraZeneca launched its "My Asthma Story" campaign, which centered on a branded YouTube 
channel for its asthma drug Symbicort. The channel featured testimonial videos from "ordinary people" sharing their stories about coping with the challenges of asthma, with each video demonstrating how Symbicort became an integral part of their regimen to manage asthma [42]. The accompanying website invited Symbicort users to upload videos about their own experiences with the drug. According to AstraZeneca, submitted videos were reviewed by a panel of legal, regulatory, and compliance experts, with selected videos appearing on the Symbicort YouTube channel [42].

Although many industry commentators initially praised the ingenuity of the My Asthma Story campaign, the campaign was abruptly discontinued in 2010, likely over fears of regulatory non-compliance. In particular, it can be a challenge to meet the FDA rules around "fair balance" (i.e., the need to present an accurate and fair assessment of the risks and benefits of the drug) in the patient testimonial video format. In a similar campaign developed by Sanofi-Aventis called whyinsulin.com, to comply with the FDA regulations, patient testimonial videos were interrupted by a blue screen featuring "important safety information", which significantly detracted from the authenticity of the videos [43]. In November 2010, a complaint filed with the US Federal Trade Commission alleged that Sanofi-Aventis had paid spokespeople to pose as typical consumers on the whyinsulin.com website [44]. Subsequently, the whyinsulin.com website was taken down in 2011. Similar concerns around the inability of pharmaceutical marketers to meet "fair balance" requirements in the US have also been raised in the context of other social media platforms, perhaps most notably in Twitter posts, which are limited to 140 characters or less [15].

Another potential complication introduced by social media is that health care professionals or other "experts" may promote a particular drug product through their personal blog or website. Greene and Kesselheim argue that it is important for regulators to address the issue of disclosure of financial interest in all media, including social media [15]. Social media also provides a powerful new means for the pharmaceutical industry to identify "key online opinion leaders" [5]. Moreover, even where a physician or other health care professional has no affiliation with the pharmaceutical manufacturer, Canada's regulations on DTCA restrict the ability of health professionals to promote specific health products on their personal sites. As an illustration, in July 2011, Health Canada issued an advisory on its website which warned physicians that "if physician Web sites promote specific products, they must comply with the [Food and Drugs] Act and its associated regulations" [45].

Another potential violation of DTCA regulations might arise if celebrities or other influential figures discuss their successes with a particular pharmaceutical product [46]. For example, pharmaceutical marketers could "support third-party bloggers, posters, and Twitter users who make flattering claims and discredit negative claims about their products in online discussions" ([15], p. 2088). As an example, a drug company in the US entered into a partnership with a professional race car driver, who also happened to be an avid Twitter user and diabetic. The race car driver began to "tweet" about his success with two insulin products produced by the drug company, but also included the drug's generic name and a link to information about the drug's risks and benefits [46]. However, although this type of ad might be permitted in the US, it would violate Canada's DTCA restrictions if it mentioned a specific drug product. Nonetheless, a drug company in Canada may sponsor a celebrity or well-known scientific or medical expert to spread the word about a disease-oriented or help-seeking message. For example, Janssen's Canadian Living Well with Psoriasis campaign features a video testimonial from a Canadian actor describing the challenges of living with psoriasis [47]. 


\subsection{Consumer Propagation and Viral Marketing}

One of the most unique features of social media technologies is the ability of everyday users to become a broadcast source, either through creating their own message or propagating a message from another source. The use of social networks to achieve marketing objectives can sometimes rise to the level of "viral marketing" when the self-replicating nature of popular messages in social media is analogous to the spread of viruses, particularly computer viruses [48].

When and how the message is delivered, as well as the medium chosen, impacts the determination of its promotional content [24]. In the policy statement The Distinction between Advertising and Other Activities, Health Canada indicates that the broader the target audience, the more likely the message will be considered to be promotional [24]. Social media platforms tend to be informal in nature and, in most cases, are widely available to a lay audience. Arguably, advertisers who participate in popular social media sites do so with the express purpose of wanting to spread their message to as wide an audience as possible and many advertisers launch campaigns on multiple social media sites concurrently. For example, Janssen's Canadian Living Well with Psoriasis campaign feature a website, a Facebook page, a Twitter feed, a YouTube channel, and iPhone/smartphone apps, presumably in an effort to reach as wide an audience as possible [47]. As such, the context of social media may give industry-sponsored health information a certain promotional aspect.

In the policy statement, Health Canada further indicates that "[w]here the same message is delivered repeatedly, the message is more likely to be considered as advertising" [24]. Although in traditional forms of push media such as television, radio, and print, the advertiser alone controls the frequency of the message through their advertising budget, with social media the frequency of message delivery depends significantly upon consumer participation and propagation. It has become common practice for websites in all sectors of the economy to include "widgets" that allow users to share a website or page through popular social media sites such as Twitter and Facebook with a single click. Such widgets are intended to allow a particular website or message to be propagated as easily as possible and are often included on pharmaceutical websites, particularly those oriented toward a particular cause or disease.

Advertisers may also incorporate a variety of different incentives into their social media campaigns in an effort to encourage consumers to spread a sponsored message through their own social networks: pharmaceutical marketers may run contests, make donations to a charity based on the number of times the message is shared, or design games or apps to increase the entertainment factor of the site. For example, in 2011, Sunovion created a Facebook game around its sleep medication Lunesta called "Follow the Wings". To encourage users to share the game, Sunovion teamed up with the charity CARE and pledged to contribute $\$ 1$ to CARE the first time a user played the game and every time a user shared the game with a friend [49]. As another example, in its Canadian "Start Something with Alesse" campaign, Pfizer launched a contest where young women can submit innovative project proposals and the winner is determined based on votes from online users, which encourages contestants to share the message broadly through their social networks in order to gain votes [50]. As such, in the context of social media, an assessment of message frequency should arguably take into account the measures taken by the advertiser to incentivize consumers to spread the message through their social networks. 
Consumer propagation is almost certainly the most difficult form of "marketing" to regulate since it is the consumers themselves, rather than the promoter, who are primarily responsible for spreading the message. In addition, consumer propagation is likely the most borderless form of advertising since it follows lines of social connectivity that reach every corner of the globe. Any attempts at regulation would probably have to be limited to rules restricting the drug company from participating in the further propagation of viral messages, or rules around targeting such campaigns. Unfortunately, attempting to regulate viral marketing raises the specter of censorship because restricting the practice would likely require clamping down on the ability of individuals to freely spread messages on the Internet.

\subsection{Targeted Marketing}

Although traditional advertising media do allow limited forms of targeted marketing (e.g., advertising arthritis pain medication in a magazine aimed at seniors), social media technologies represent an unprecedented opportunity to corner the target audience. Social media sites give promoters the opportunity to target their advertisements to particular audiences based on information from users' profiles and online activity; advertisers can target users not only based on demographic information and interests listed in a user's profile, but may even advertise to friends and connections of users who have shown an interest in their page [51].

There is a diversity of ways in which the pharmaceutical industry could use these targeted marketing opportunities to narrow the focus of their advertising campaigns to those users who are most likely to have an interest in their products. For example, advertisers could promote birth control pills to women between the ages of fourteen and forty, or arthritis pain medication or cholesterol-lowering drugs to people over age fifty. There are even potential benefits to such targeted marketing since it could be used to direct advertisements towards more appropriate audiences - for instance, excluding children under the age of eighteen from seeing the ads. However, there is a dark flipside to this if certain drugs are specifically targeted at vulnerable groups such as children or the elderly. Targeted marketing might raise controversy if, for example, it promoted sleeping pills or anti-anxiety drugs to students in high-stress majors such as law and medicine. Ultimately, given the potential for pharmaceutical advertisers to use targeted marketing to direct their online campaigns at particular groups or demographics, this is another area of social media marketing that could benefit from greater regulatory guidance.

\section{Search Engine Advertising}

Another form of targeted marketing that has transformed online commerce in recent years is sponsored search engine advertising where promoters pay search engines such as Google, Bing, and Yahoo! for traffic from the search engine to their website [51]. Most commonly, the sponsored search results are driven based on specific key words that a promoter chooses to associate with its ad. However, with the newest wave of sponsored search results, search engines like Google actually provide "personalized ads" by collecting and compiling information about a user's online activities in order to show consumers ads related to websites visited, recent searches and clicks, or information from e-mail inboxes [52]. According to L2, approximately $70 \%$ of pharmaceutical brands engage in paid search advertising on Google or Bing [9]. 
Sponsored search results have generated a fair amount of criticism. The US Federal Trade Commission has reported that search engines do not adequately label sponsored links, and various studies have shown that searchers are often unaware of the distinction between sponsored links and non-sponsored links [51]. And while the same studies reported that searchers who are aware of the distinction tend to find sponsored links to be less relevant, there are nonetheless a significant number of consumers who are persuaded to click on sponsored links instead of the natural search results (indeed, if this were not the case, advertisers would not invest in sponsored links) [51]. As such, sponsored search results advertisers have a clear potential to manipulate the information that consumers access online.

As with any other form of pharmaceutical DTCA, search engine sponsored link advertisement and the keywords that generate these links are subject to the Health Canada regulations. Guidance from PAAB suggests that for websites for prescription drugs, the aggregate of the keywords, sponsored link, the landing page (i.e., the page accessed by a web browser upon following a link) and its URL may not go beyond the name, price, and quantity restriction required for reminder ads [34]. Similarly, for websites for drugs for the treatment of Schedule A diseases, the aggregate of the keywords, sponsored link, the landing page, and its URL may not allude to the therapeutic use [34]. Finally, for disease-oriented websites, the keywords, sponsored link, the landing page and its URL may not contain the drug name [34]. However, these restrictions do not currently apply to organic keyword results.

\subsection{The Role of Unbranded Advertising}

In the US, where full-product ads are permitted, disease-oriented or help-seeking advertising have traditionally played a limited role in pharmaceutical marketing campaigns, accounting for only about four percent of total DTCA in the US in 2008 [15]. This is largely due to the fact that unbranded sites typically generate much lower traffic than a branded site and also create the danger that a competing brand might benefit from the other's unbranded efforts [9]. However, as more and more consumers turn to the Internet as a source of health information, unbranded initiatives, particularly those focused around a particular disease or condition, allow pharmaceutical companies to connect with patients throughout the stages of encounter with a disease and potentially drive them into the "marketing funnel" [9]. Further, when unbranded marketing initiatives engage a variety of social media platforms and online marketing techniques, there are ample opportunities to push the advertisement to a wider audience than those who might actively seek information from major general health and medical websites [53].

Unbranded marketing campaigns are often better suited to social media platforms than corporate initiatives. Most consumers tend to trust "unbranded" information found on major third party health and medical websites more than "branded" information on industry-sponsored websites: PriceWaterhouseCooper revealed that consumers were more likely to trust information posted by doctors and hospitals compared to insurers and drug companies [11]. In particular, only thirty-seven percent of respondents said they would trust information posted by a pharmaceutical company [11]. The most successful social media campaigns tend to be those that focus on "socially-relevant" content such as causes, events, support, and services; that is, "[a]n unbranded approach can offer a more human and personal way for pharmaceutical companies to participate in social media" [53]. In general, 
consumers are more likely to engage with and support a relatable cause on a social media platform than a particular pharmaceutical product [53]. For example, consumers would be more likely to follow a Facebook page aimed at raising awareness about depression than they would be to follow a page for a branded antidepressant.

As pharmaceutical companies increase investment in social media marketing, a significant proportion of this investment will likely go towards unbranded campaigns aimed at raising awareness about a particular disease or condition and encouraging patients to talk to their doctor about treatment options. However, what role the pharmaceutical industry should play in providing health information is at the heart of the debate around the risks and benefits of DTCA. Critics argue that a key objective of for-profit corporations, in any sector of the economy, is to maximize profit. Consequently, pharmaceutical companies may find it profitable to use persuasion and exaggeration in their marketing activities, which arguably makes it unlikely that the health information provided by drug companies can be considered as strictly informative [17].

Health information provided by industry often places a strong emphasis on talking to your doctor about treatment options, as this is the route through the company may be able to generate more prescriptions for their drug product ${ }^{4}$. Overall, discovering fair and balanced information on the Internet may become more difficult as the pharmaceutical industry itself becomes a more dominant source of online health information ${ }^{5}$. This is particularly true when, as described above, drug companies pay search engines like Google to increase the prominence of their sites in search results [9] — the effect may be that more objective health information sites run by patient interest groups or medical organizations may begin to be crowded out by information sites sponsored by drug companies.

\section{Regulatory Aspects}

There are many challenges in regulating DTCA, both in general and in the context of the Internet and social media. Under the current regulatory system, Health Canada is responsible for interpreting and enforcing drug advertising regulations, including establishing policies to effectively regulate marketed health products, issuing guidelines for the interpretation of the regulations; and overseeing

4 For example, on the Canadian Living Well with Psoriasis website [47] sponsored by Janssen there is an Impact Questionnaire and a Severity Calculator aimed at determining the seriousness of a user's psoriasis. Even if the user indicates that psoriasis never impacts their life, the Impact Questionnaire still suggests that the user should consult their doctor if they have any particular concerns. The Severity Calculator inquires about whether the patient is receiving treatment, if the treatment is working, and whether there is anything about current treatment that the patient does not like - nearly all responses lead to the conclusion that the user should talk to their doctor about different treatment options. The site even provides a "Dermatologist Finder" tool to help users locate a dermatologist in their area.

5 It is worth recognizing that the pharmaceutical industry is certainly not the worst offender when it comes to the production of questionable health information. The Internet is brimming with claims of miracle cures, natural remedies, and new age treatments from dubious sources. Unfortunately, many consumers lack the knowledge necessary to discern between legitimate and questionable sources of health information. However, there are already some initiatives aimed at facilitating access to reliable health information online. One such initiative is HONcode, which is described as "the oldest and most used ethical and trustworthy code for medical and health related information available on [the] Internet." The HONcode website provides a search engine where users can seek out health information on a wide range of sites that have undertaken to respect the HONcode ethical standard of offering quality health information [54]. 
regulated advertising activities [55]. However, Health Canada does not directly review DTCA materials for compliance with the regulations. Rather, the preclearance of advertising for marketed health products is carried out through a self-regulatory and voluntary system in which independent preclearance agencies review and pre-clear advertising material to help advertisers ensure compliance with the regulatory provisions of the Food and Drugs Act, the Controlled Drugs and Substances Act and respective regulations [56]. Advertising preclearance agencies use Health Canada's guidance documents and their own codes of advertising to ensure that advertising material is "accurate, balanced and evidence-based" and is consistent with the license for the health product [56]. The following section describes three different regulatory approaches - direct government regulation, independent third party oversight, and industry self-regulation - and some of the advantages and disadvantages of each as they currently exist in Canada.

\subsection{Direct Government Regulation}

Proponents of direct government regulation argue that it offers a number of advantages "in terms of visibility, credibility, accountability, compulsory application to all...greater likelihood of rigorous standards being developed, cost spreading... and availability of a range of sanctions" [57]. Unfortunately, many of these purported benefits fail to play out in practice. In recent years, a significant amount of criticism has been directed against Health Canada for its lack of enforcement of advertising regulations. According to Gardner and colleagues, "[r]esponse to complaints tends to be slow, probably reflecting Health Canada's undercapacity to regulate DTCA, and, arguably, ineffectual" ([6], p. 425). Similarly, a 2004 House of Commons Standing Committee on Health report stated that "Health Canada has abrogated its clear responsibility to enforce the existing rules" ([58], p. 10). Some sources report that no company has been fined or had any other sanctions imposed against it by Health Canada for any promotional violation, including DTCA, since 1978 [59].

While all advertising preclearance agencies, including the ASC and PAAB, offer mechanisms to resolve complaints on advertising for authorized health products, Health Canada is directly responsible for handling any complaints about prescription drug advertising and information aimed directly at Canadian consumers [56]. Any complaints of this nature received by an advertising preclearance agency must be referred to Health Canada [56]. Within Health Canada, complaints are investigated by the Health Products and Food Branch Inspectorate. However, the branch will generally not proceed against an advertiser unless it can demonstrate that the ad is deceptive or poses significant risk to the health of Canadians [58]. With respect to enforcement, Health Canada has indicated that "its efforts range from education and voluntary compliance to warning letters and prosecutions that could result in fines, injunctions or imprisonment" ([58], p. 9).

\subsubsection{Challenges in Enforcement}

Canada is certainly not the only country that has struggled with direct regulation of pharmaceutical advertising. Lexchin points out that "fiscal pressures in almost all countries have prevented government agencies from effectively policing pharmaceutical promotion" ([18], para. 101). Given the considerable return on investment that the pharmaceutical industry can achieve from sales generated through DTCA, government regulatory bodies generally lack the resources necessary to implement 
strict enough sanctions to make it economically rational for firms to adhere to regulations. Further, government regulators are often criticized for lacking the expertise necessary to regulate the industry [18]. Lexchin points to the challenges faced by the FDA in attempting to directly regulate DTCA in the US: the FDA is chronically under-funded; staff are consistently overwhelmed by the volume of material that they have to deal with; and they are becoming increasingly unwilling to confront firms guilty of promotional violations due to an inability to adequately reprimand violators [18].

In Canada, the regulatory system responsible for approving prescription drugs is largely funded by the pharmaceutical industry through a user-fee system. Some critics argue that through these financial contributions, the pharmaceutical industry has gained significant influence within the drug regulatory system and uses this influence to request a disproportionate distribution of funding towards fast drug approval, rather than long-term safety monitoring [57]. Non-enforcement of legislation by government may be seen "as a soft way of managing the pressure from industry" [60]. Alternatively, non-enforcement may simply stem from an unwillingness to take on the pharmaceutical industry in costly and time-consuming legal battles [60].

In recent years, Health Canada has been credited with improving its response times to complaints - at least for those referred by the advertising preclearance agencies. In general, response times have improved year over year [28]. Moreover, at an April 2010 meeting between Health Canada and the advertising preclearance agencies, the meeting attendees acknowledged that advertising issues that are referred to Health Canada from the advertising preclearance agencies are "not straightforward and often require consultation among various areas within Health Canada", and further "often require policy work, issue analysis, or legal advice, which can all be time consuming" [61]. Further, urgent issues, such as advertising for unauthorized products, are addressed on a priority basis, particularly if they present a health risk [61].

\subsubsection{Increasing Deterrence}

Even if Health Canada did regularly levy sanctions for breaches of the DTCA regulations, the current maximum penalties allowed under the Food and Drugs Act are trivial at best. Section 31 of the Food and Drugs Act provides that for a contravention of the Act or its regulations, a party is liable for a maximum fine of $\$ 5000$, a term of imprisonment of up to three years, or both [23]. Fortunately, the maximum penalty provisions under the Food and Drugs Act may be set to increase in the near future if the new drug safety legislation proposed in Bill C-17 is passed by the Canadian Government. The new maximum fine provisions in Bill C-17 are exponentially larger than those under the current legislation: Under S. 31.2(a), the new maximum fine is $\$ 5$ million-a 1000 -fold increase over the current maximum [62]. Further, under S. 31.7, where an offence is found to have been committed or continued over multiple days, the maximum available fine is multiplied by the number of days, thus significantly increasing the potential upper limit of fines [62]. Finally, under S. 31.4, where a person "knowingly or recklessly causes risk of injury to human health in the commission of an indictable offence", there is no maximum to the fine that a court may impose ([62], s. 31.4(a)).

Apart from exceptional circumstances where personal liability is found, the threat of imprisonment is rarely applicable to pharmaceutical companies since corporations cannot be imprisoned. However, Bill C-17 makes it clear that individuals within a corporation may be held liable for offences 
committed by that corporation. In particular, Section 31.6 states that where a corporation commits an offence, "any of the [corporation's] directors, officers or agents or mandatories who directs, authorizes, assents to or acquiesces or participates in the commission of the offence is a party to the offence and is liable on conviction to the punishment provided for by this Act, even if the person is not prosecuted for the offence" ([62], s. 31.6). This provision makes it clear that where an individual within a corporation is found to be a party to the offence, they may be found personally liable for the offence such that they will not be shielded from penalty by the corporate structure. Bill C-17 will hopefully be passed later in 2014 .

Another important aspect of deterrence is "public shaming"- that is, ensuring that the circumstances of the contravention become a matter of public record. At a meeting between Health Canada and the Canadian advertising preclearance agencies in April 2009, the ASC and PAAB noted that both agencies have recommended that Health Canada publish final rulings on advertising complaints that have been resolved in order to "increase transparency, discourage noncompliance, and to share information regarding past experiences and precedents" [27]. Although Health Canada acknowledged the potential advantages of posting this information online, they noted that they face significant limitations due to the need to comply with the Privacy Act - the only exception being where the information is related to a significant impact on public health. However, Health Canada emphasized that they currently post recalls, warning letters, and advisories and are developing the Compliance and Transparency Initiative which may include publishing outcomes of Health Canada's compliance work or generating summary reports without specific details on the complaints to show what actions are taken to resolve the advertising complaints [27].

\subsubsection{Recognizing the Limitations of Government Oversight}

Given the lack of enforcement of existing regulations in traditional media, there is understandably a significant amount of skepticism about the ability of Health Canada to effectively regulate DTCA on Internet and social media platforms. Health Canada appears to have neither the resources nor the political will to dedicate much attention to enforcing regulation on the Internet. Unfortunately, both the insubstantiality of the available sanctions and Health Canada's lack of enforcement have led many drug companies to adopt an "it is easier to ask forgiveness than permission" approach to advertising. That is, many drug companies are increasingly pushing the envelope with their DTCA campaigns in order to test the limits of what is permitted.

While Health Canada will continue to play an important, if somewhat ineffective, role in the provision and enforcement of DTCA regulations in both traditional and digital mediums, there is a concurrent need to consider other avenues besides direct government regulation for the effective regulation of pharmaceutical social media marketing. Both industry self-regulation and independent third party oversight may arguably be an important complement to the enforcement of DTCA regulations in the Internet and social media context.

\subsection{Independent Third-Party Oversight}

Health Canada mandates two agencies to review and pre-clear advertising materials for prescription drugs directed at consumers: the ASC and the PAAB. Specifically, these two agencies "provide advisory opinions on messages directed to consumers for prescription drugs and on educational 
material discussing a medical condition or disease" [63]. In addition, advertising material that is distributed to physicians, or to patients through physicians, is reviewed and pre-cleared by the PAAB in accordance with the PAAB Code of Advertising Acceptance.

One potential advantage of third-party oversight is that independent agencies generally have more flexibility in their structure and mandate than government regulators and may enjoy a less adversarial relationship with the pharmaceutical industry. However, to be effective, any oversight body must have clear authority to levy sanctions and to report violations to the public. Lexchin cautions that in New Zealand, where DTCA is largely governed by the independent Advertising Standards Complaints Board, such regulations are often ineffective because the board lacks the power to make decisions binding and enforceable [18]. Indeed, this is already a difficulty faced by the PAAB since the organization has no authority to levy financial penalties on companies that breach its code, and companies are rarely ordered to run corrective advertising [18]. In addition, Lexchin points out that although the PAAB is independent of the pharmaceutical industry, the majority of members on its board come from organizations that benefit financially, either directly or indirectly, from advertising [18].

Since preclearance is not mandatory, advertisements may technically be released to the general public without being reviewed by government regulators or their delegated bodies [6]. However, although the system is voluntary in that the review and preclearance of DTCA materials is not strictly legally required by Health Canada, most broadcasting and mass-media outlets in Canada will not publish an advertisement without ASC or PAAB approval [64]. Further, preclearance of physician materials and adherence to the PAAB Code is mandated for all members of Canada's Research-based Pharmaceutical Companies (Rx\&D), a national association representing the brand name pharmaceutical industry [64]. Promotional material that has been successfully pre-cleared by the PAAB or the ASC may be marked with the PAAB or ASC logo, respectively, to signify the approval of each preclearance agency.

While preclearance is standard practice for traditional media such as print, radio, and television, preclearance of consumer-directed online materials appears to be less frequent. For example, while the Canadian drug product websites for blockbuster drugs such as Nexium ${ }^{\circledR}$ (AstraZeneca), Singulair ${ }^{\circledR}$ (Merck), and Lantus (Sanofi-Aventis) all bear the PAAB seal of approval, the websites for other major drugs such as Lipitor $^{\circledR}$ (Pfizer) and Advair ${ }^{\circledR}$ (Bristol-Meyers Squibb) do not. Moreover, many pharmaceutical promotional materials on social media platforms do not bear either the PAAB or ASC seal of approval. Thus, while PAAB or ASC review appears to be common practice for DTCA materials in traditional media-likely due in large part to media outlet rules that require such review before publication - some drug product websites, and many social media campaigns, do not undergo such preclearance review.

\section{Proposals for Mandatory Preclearance}

Due to the potential for DTCA materials to be released to the public without being subject to any type of review, some commentators have suggested that advertising preclearance of DTCA materials by the PAAB or ASC should be mandatory, rather than voluntary. Regis, for example, argues that an advantage of mandatory preclearance would be the possibility for Health Canada to require a mention of approval in ads that successfully make it through the preclearance process, which would help 
distinguish Canadian ads from their American counterparts, as well as indicate which drugs are available in Canada [65]. She further suggests that to relieve Health Canada of any additional costs, this preclearance service could be financed by the pharmaceutical companies through a user fee system, as is done now under the voluntary system [65].

Although many pharmaceutical companies already take advantage of the voluntary "advisory opinion" services offered by the $\mathrm{PAAB}$ and $\mathrm{ASC}$, the industry would likely protest against a mandatory preclearance system due to increased cost, delay, and loss of control. Further, both the ASC and PAAB would likely have to significantly increase their resources to accommodate the increased workload created by a mandatory preclearance requirement. Enforcement of the system would also be cumbersome. In the US during FDA hearings on issuing social media guidance in 2009, the idea of having a FDA "seal of approval" on FDA-reviewed online content was raised as a potential means to ensure the credibility of information on drug risks and benefits presented through social media. However, a major shortcoming of this approach is that the FDA does not have the resources to adequately police pharmaceutical promotion in social media [15]. Due to the smaller size of the organization, Health Canada would likely face even greater resource limitations in trying to enforce such a "seal of approval" system.

Overall, the advertising preclearance agencies could potentially have an important role to play in the regulation of Internet and social media marketing campaigns, especially considering that these agencies are already developing expertise in this area — and have certainly done far more than Health Canada thus far in offering social media guidance. However, as long as preclearance of DTCA materials remains voluntary, many pharmaceutical advertisers will likely continue to forgo preclearance of their online marketing campaigns simply because they can - and because they likely have little fear of reprisal from Health Canada even if they do contravene the regulations.

\subsection{Industry Self-Regulation}

In general, self-regulation refers to a regime where the industry or profession rather than the government is responsible for regulation. Systems of self-regulation commonly exist in combination with government regulation, with an industry or profession being given authority to govern itself while still relying on a state agency to carry out certain functions such as administration and adjudication of complaints [57]. While self-regulatory bodies are usually granted a fair amount of autonomy with respect to rulemaking, monitoring, enforcement, and sanctions, the government will usually retain ultimate authority at some level [57].

There are a number of advantages that are commonly claimed for self-regulation. First, self-regulatory bodies often have more expertise and technical knowledge of practices in their industry than government regulators or independent agencies [57]. Self-regulation may be more cost-effective in terms of the formulation and interpretation of standards, monitoring, and enforcement, and also allows for administrative costs to be internalized by the industry and thus make no demands on taxpayer funds. In addition, self-regulation often allows for greater flexibility than direct government oversight as a result of less formal rules and processes. Finally, self-regulation also tends to reduce the adversarial stance between government and industry [57]. 
In Canada, pharmaceutical industry self-regulation stems not from delegated government power, but from within the private sector itself. Since DTCA is primarily the domain of innovative pharmaceutical companies, the primary self-regulatory body as it relates to DTCA is Rx\&D, which has established a Code of Ethical Practices to govern the relationship between its member companies and various stakeholders. The 2012 version of the Code requires all members to comply with all applicable provisions of the Health Canada regulations, the PAAB Code of Advertising Acceptance and the ASC Code of Advertising Standards. A breach of any of the above codes of regulations may be deemed by the Rx\&D Industry Practices Review Committee (IPRC), the body responsible for adjudicating complaints of breaches, to constitute a breach of the Rx\&D Code [66].

\subsubsection{The Complaint Process}

The majority of the complaints before the IPRC are brought by pharmaceutical companies against competing firms. Arguably, in a highly competitive industry such as pharmaceutical sales, "the desire of individual companies to prevent competitors from gaining an edge can be harnessed to serve the public interest..." ([18], para. 103). However, Lexchin argues that although self-regulation can inhibit competition to some degree, he notes that the Rx\&D Code "relies on complaints of breaches before it takes actions, rather than proactively monitoring compliance" and that "the majority of the members of the committee come from the pharmaceutical industry" ([18], para. 104). Lexchin further notes that the penalties for breaches of the code are relatively minor [18], i.e., $\$ 25,000$ for a first infraction, $\$ 50,0000$ for second infraction, $\$ 75,000$ for a third infraction, and $\$ 100,000$ for each additional infraction within a calendar year [66].

All complaints of Rx\&D Code infractions since 2006 are published on the Rx\&D website for a period of 24 months [66]. However, few details are provided on these cases and specific names of the companies and products involved are only published where a breach is found by the IPRC. Consequently, the deterrent impact of publishing infractions on the Rx\&D website is likely to be limited since the summaries listed provide few details on each allegation or violation and the finding of an infraction is not publicized in any other way. Rx\&D should make its decisions more widely available and remove the 24-month time limit on the posting to increase the deterrent effect of the finding of an infraction and to help establish a clearer public record of what sorts of activities contravene the Code.

\subsubsection{Self-Regulation of Online DTCA}

While industry self-regulation is certainly not a substitute for direct government regulation, there is certainly potential for the two systems to work in tandem, particularly given the void that has been left by Health Canada's lack of enforcement activities. Moreover, self-regulation is one area that has the potential to work well in the Internet and social media context. As an emerging form of pharmaceutical marketing, many drug companies are paying close attention to the activities of their competitors in planning their own social media campaigns. Moreover, as noted by Greene and Kesselheim, "[m]anufacturers are in a better position to monitor online discussions about their products: most US companies that depend on copyright and trademark recognition currently engage in brand-protection activities through aggressive surveillance and litigation" ([15], p. 2088). As such, many drug 
companies may be eager to report a competing firm if they feel their competitor is pushing the rules too far and gaining an unfair marketing advantage. That said, such industry self-reporting is unlikely to take off unless and until Health Canada more clearly articulates how existing DTCA rules apply in the Internet and social media context. In particular, although a breach of the Food and Drugs Act or its regulations can constitute a breach of the Rx\&D Code of Ethical Practices, as long as the rules are unclear, likely neither Rx\&D nor its members will have much confidence to act against a potential infringing firm. Overall, as stated by Greene and Kesselheim, "[g]iven the potentially important health implications of drug promotion in [social] media, regulators and manufacturers will have to share the responsibility for oversight" ([15], p. 2089).

\section{Conclusions}

Despite a slow start, pharmaceutical social media marketing is now becoming widespread and is only expected to increase in the future. And while Health Canada has made it clear that the existing DTCA regulations apply to the Internet and social media context, this new medium remains an uncertain landscape for both pharmaceutical advertisers and regulators. Many social media campaigns have proven to be short-lived, usually due to a lack of consumer interest or real or perceived non-compliance with DTCA regulations. Pharmaceutical advertisers are quickly learning that consumers are more likely to engage with and support an "unbranded" educational message on a social media platform, particularly where it is coupled with a relatable cause, than a particular branded pharmaceutical product. While the effectiveness of a social media initiative depends on a variety of factors such as disease category, brand goals, product situation, and the regulatory environment, there are several recent trends that suggest the growing importance of online advertising as a useful complement to other marketing initiatives. Ultimately, in the rapidly evolving world of social media, drug companies will have to be increasingly creative if they want to stay relevant, particularly as more and more competitors enter the social media sphere.

While the experiences of drug regulators in the US suggest that the issuance of detailed social media guidelines may be more trouble than it is worth, the FDA now includes aspects of social media in more general guidance documents. As such, Health Canada appears to be lagging behind the FDA in addressing the issue of social media marketing. In particular, there are a number of unique aspects of social media - namely UGC, consumer propagation and targeted marketed - that make the application of the existing regulations to this new medium an uncertain process. While the rules around UGC are quite clear - manufacturers are responsible for site content, regardless of its source - there is a need for more specific guidance around the duty to report adverse events and acceptable use of UGC in promotional activities. Health Canada should also consider some general principles regarding appropriate targeted marketing practices, particularly as they relate to vulnerable populations.

The enforcement of DTCA regulations, even in traditional media, has often proven to be a challenge, which raises serious questions about the ability of Health Canada to effectively regulate the Internet and social media. While the exact reasons for Health Canada's lack of enforcement activities are unclear, the trend is likely at least partially explained by resource limitations and a reluctance to engage in lengthy and expensive legal battles with industry. Overall, given that pharmaceutical advertising on Internet and social media platforms does not currently appear to be a priority for Health 
Canada, direct government regulation alone is unlikely to be sufficient to ensure compliance with the DTCA regulations. Further, given that social media is still largely uncharted territory for the pharmaceutical industry, drug firms will likely be paying close attention to the activities of their competitors in this new medium - and may be more than happy to complain to Rx\&D if they feel another company is gaining an unfair advantage by pushing the limits of the DTCA regulations too far. Nonetheless, industry self-regulation still has significant weaknesses and should only serve as a complement to the more central enforcement activities of Health Canada and the advertising preclearance agencies.

There is no question that consumers want access to more information about drugs and their safety and effectiveness. The response to the pharmaceutical industry's burgeoning interest in social media should not simply be limited to restricting or regulating the advertising of drug products via digital media. Rather, the Internet and social media is equally available to health care professionals, advocacy groups, government, and consumers as a tool to spread their own health information and such resources should be developed as an alternative to pharmaceutical industry promotion. More than a decade ago, the high-profile Romanow Report on the future of health care in Canada expressed clear opposition to DTCA and recommended the establishment of a National Drug Agency, which among its various roles would "communicate evidence-based information and guidance to both health professionals and to patients, using various media including the Internet" ([67], p. 202). While Health Canada provides access to its online Drug Product Database, which offers detailed information about all drugs approved for use in Canada, much of the information provided is quite technical in nature and is not targeted at consumers. There is an opportunity to make this information more easily available to consumers through a user-friendly interface accessible through a single government-sponsored health information portal. This would be an important step forward in providing Canadians with access to reliable and neutral online health information, particularly on drug products that are approved for sale in Canada.

\section{Acknowledgements}

The author would like to acknowledge the invaluable guidance and commentary provided by Professor Colleen Flood during the preparation of the thesis on which this paper is based. She would also like to thank Barbara Mintzes for valuable commentary provided on an earlier draft of the thesis. Special thanks to Brenda Robson for her excellent editorial assistance on multiple versions of this paper. The original version of the thesis was completed for the LL.M. program at the University of Toronto Faculty of Law in 2012 [68].

More recent work adapting this paper from the thesis was supported by a grant from Genome Canada.

\section{Abbreviations}

ASC: Advertising Standards Canada;

DTCA: direct-to-consumer advertising;

FDA: Food and Drug Administration;

PAAB: Pharmaceutical Advertising Advisory Board;

Rx\&D: Canada's Research-based Pharmaceutical Companies;

UGC: user-generated content. 


\section{Conflicts of Interest}

The author declares no conflict of interest.

\section{References and Notes}

1. Bryan A. Liang, and Timothy K. Mackey. "Prevalence and Global Health Implications of Social Media in Direct-to-Consumer Drug Advertising." Journal of Medical Internet Research 13 (2011): e64. doi:10.2196/jmir.1775.

2. Ann Silversides. "Charter Challenge of Ban on Direct-to-Consumer Advertising to Be Heard by Ontario Court in Mid-June.” Canadian Medical Association Journal 181 (2009): E5-6.

3. Barbara Mintzes. "What Are the Public Health Implications? Direct-to-Consumer Advertising of Prescription Drug in Canada." Health Council of Canada, January 2006. Available online: http://www.healthcouncilcanada.ca/tree/2.38-hcc_dtc-advertising_200601_e_v6.pdf (accessed on 8 July 2014).

4. Jeff Chester, Ed Mierzwinski, John M. Simpson, and Pam Dixon. "In the Matter of Online Health and Pharmaceutical Marketing That Threatens Consumer Privacy and Engages in Unfair and Deceptive Practices (Complaint, Request for Investigation, Public Disclosure, Injunction, and Other Relief before the Federal Trade Commission)." 23 November 2010. Available online: http://www.democraticmedia.org/sites/default/files/2010-11-19-FTC-Pharma-Filing.pdf (accessed on 8 July 2014).

5. Jeanne Lenzer. "Big Pharma would like to Befriend You." British Medical Journal 342 (2011): d4075.

6. David M. Gardner, Barbara Mintzes, and Aleck Ostry. "Direct-to-Consumer Prescription Drug Advertising in Canada: Permission by Default?" Canadian Medical Association Journal 169 (2003): 425-27.

7. Beth Snyder Bulik. "Pharmaceutical Marketing (Ad Age Insights White Paper)." 17 October 2011. Available online: http://adage.com/images/bin/pdf/WPpharmmarketing_revise.pdf (accessed on 8 July 2014).

8. Marc Iskowitz. "Pharma Poised to up Online Ad Spend eMarketer." Medical Marketing \& Media, 27 April 2011. Available online: http://www.mmm-online.com/pharma-poised-to-up-online-adspend-emarketer/article/201584/ (accessed on 8 July 2014).

9. L2. "Digital IQ Index Pharma." May 2010. Available online: www.12thinktank.com/ pharmadigitaliq/Digital_IQ_Pharma.pdf (accessed on 8 July 2014).

10. "Pharmaceutical Industry Rapidly Expanding Partnerships with New Entrants in Health Care Space, Ernst \& Young Finds." PR Newswire, 15 February 2011. Available online: http://www.prnewswire.com/news-releases/pharmaceutical-industry-rapidly-expandingpartnerships-with-new-entrants-in-health-care-space-ernst--young-finds-116209364.html (accessed on 8 July 2014).

11. Chad Terhune. "Consumers Using Social Media for Medical Information, Report Says." Los Angeles Times, 17 April 2012. Available online: http://articles.latimes.com/2012/apr/17/business/ la-fi-mo-social-health-20120417 (accessed on 8 July 2014). 
12. Adam Hooper. "“Cyberchondria' a Growing Problem.” Winnipeg Free Press, 3 January 2011. Available online: http://www.winnipegfreepress.com/arts-and-life/life/health/cyberchondria-agrowing-problem-117135708.html (accessed on 8 July 2014).

13. Statistics Canada. "Canadian Internet Use Survey." Statistics Canada, 10 May 2010. Available online: http://www.statcan.gc.ca/daily-quotidien/100510/dq100510a-eng.htm (accessed on 8 July 2014).

14. Christine S. Moyer. "Cyberchondria: The One Diagnosis Patients Miss." American Medical News, 30 January 2012. Available online: http://www.amednews.com/article/20120130/health/ 301309952/1/ (accessed on 8 July 2014).

15. Jeremy A. Greene, and Aaron S. Kesselheim. "Pharmaceutical Marketing and the New Social Media." New England Journal of Medicine 363 (2010): 2087-89.

16. Kurt C. Stange. "Time to Ban Direct-to-Consumer Prescription Drug Marketing." The Annals of Family Medicine 5 (2007): 101-04.

17. Steven G. Morgan. Canwest Mediaworks Inc. v. Attorney General of Canada, Affidavit of Steven G. Morgan, (Ontario Superior Court of Justice 2006).

18. Joel Lexchin. Canwest Mediaworks Inc. v. Attorney General of Canada, Affidavit of Joel Lexchin, (Ontario Superior Court of Justice 2006).

19. Barbara Sibbald. "Rofecoxib (Vioxx) voluntarily withdrawn from market." Canadian Medical Association Journal 171 (2004): 1027-28.

20. Rena Steinzor, and Margaret Clune. "The Hidden Lesson of the Vioxx Fiasco: Reviving a Hollow FDA." Center for Progressive Reform, October 2005. Available online: http://progressivereform.org/articles/Vioxx_514.pdf (accessed on 8 July 2014).

21. Advertising Standards Canada. "ASC Clearance Services DTCI Guide." Available online: http://www.adstandards.com/en/Clearance/ConsumerDrugs/DTCIGuideEN.pdf (accessed on 8 July 2014).

22. Health Canada. "Prescription Drug List." 20 March 2014. Available online: http://www.hcsc.gc.ca/dhp-mps/prodpharma/pdl-ord/pdl_list_fin_ord-eng.php (accessed on 8 July 2014).

23. Food and Drugs Act. R.S.C. 1985, C. F-27, n.d.

24. Health Canada. "The Distinction between Advertising and Other Activities (Policy Statement)." 12 January 1996. Available online: http:/www.hc-sc.gc.ca/dhp-mps/alt_formats/hpfbdgpsa/pdf/advert-publicit/actv_promo_vs_info-eng.pdf (accessed on 8 July 2014).

25. Health Canada. "Advertising Campaigns of Branded and Unbranded Messages (Policy Statement)." November 2000. Available online: http:/www.hc-sc.gc.ca/dhp-mps/alt_formats/ hpfb-dgpsa/pdf/advert-publicit/advert-pub_camp_final_2005-08-eng.pdf (accessed on 8 July 2014).

26. Food and Drugs Regulations. C.R.C., C. 870, n.d.

27. Health Canada. "Record of Discussions - Canadian Advertising Preclearance Agencies and Health Canada-7 April 2009." 7 April 2009. Available online: http://web.archive.org/web/2013060 3005841/http://www.hc-sc.gc.ca/dhp-mps/advert-publicit/meet-reunion/2009_04_07_rod_rddeng.php\#a5 (accessed on 8 July 2014).

28. Health Canada. "Record of Discussions - Canadian Advertising Preclearance Agencies and Health Canada-19 April 2011." 19 April 2011. Available online: http://web.archive.org/web/20130111 031108/http://www.hc-sc.gc.ca/dhp-mps/advert-publicit/meet-reunion/rod-rdd_2011_04_19eng.php (accessed 8 July 2014). 
29. Bliss Hanlin. "FDA Guidance for Pharma on Social Media and Off-Label Use." Blog. eModeration, 19 January 2012. Available online: https://www.emoderation.com/fda-guidancefor-pharma-on-social-media-and-off-label-use (accessed on 8 July 2014).

30. US Food and Drug Administration. "Guidance for Industry: Responding to Unsolicited Requests for Off-Label Information about Prescription Drugs and Medical Devices.” December 2011. Available online: http:/www.fda.gov/downloads/Drugs/GuidanceComplianceRegulatoryInformation/ Guidances/UCM285145.pdf (accessed on 8 July 2014).

31. Dale Cooke. "The FDA Social Media Guidance: The Path Forward." MediaPost Blog: Marketing: Health, 10 February 2012. Available online: http:/www.mediapost.com/publications/article/167499/ the-fda-social-media-guidance-the-path-forward.html (accessed on 8 July 2014).

32. Advertising Standards Canada. "DTCA Rx Checklist and DTCI Guide-Updated to Include Social Media!” Enews, Fall 2011. Available online: http://www.adstandards.com/en/ASCLibrary/ newsletters/fall2011/newsletter_clearanceNews.aspx (accessed on 8 July 2014).

33. Dominic Tyer. "ABPI: Nothing to Stop Pharma Using Social Media." PMLiVE Digital Intelligence Blog, 27 January 2012. Available online: http://www.pmlive.com/blogs/digital_ intelligence/archive/2012/jan_2012/abpi_uk_pharma_use_social_media (accessed on 8 July 2014).

34. Patrick Massad. "Incorporating a Strategic Regulatory Though Process Into You SMM Planning...To Develop a Successful Social Media Marketing Campaign with PAAB.” Slideshow presented at Pharma e-Marketing Canada 2010, Toronto, Canada, 1 November 2010.

35. Jennifer McKenzie, and Ainslie Parsons. "Guidance on Social Media Marketing for Pharmaceuticals." Bereskin \& Parr Intellectual Property Law, 25 May 2011. Available online: http://www.bereskinparr.com/Article/id49/?srch=guidance\%20on\%20social\%20media (accessed on 8 July 2014).

36. Matthew Snodgrass. "Facebook Page Commenting Changes." Common Sense, 13 April 2011. Available online: http://blog.wcgworld.com/2011/04/facebook-page-commenting-changes (accessed on 8 July 2014).

37. Eric Eldon. "Facebook No Longer Blocking Comments for (Most) Pharmaceutical Pages." Inside Facebook, 24 May 2011. Available online: http://www.insidefacebook.com/2011/05/24/facebookno-longer-blocking-comments-for-most-pharmaceutical-pages/ (accessed on 26 April 2014).

38. Health Canada. "Guidance Document for Industry-Reporting Adverse Reactions to Marketed Health Products.” 2 March 2011. Available online: http:/www.hc-sc.gc.ca/dhp-mps/alt_formats/ pdf/pubs/medeff/guide/2011-guidance-directrice_reporting-notification-eng.pdf (accessed on 8 July 2014).

39. John Mack. "Janssen to Shut Down Psoriasis 360 FaceBook Page Due to Lack of Commitment." Pharma Marketing Blog, 22 March 2012. Available online: http://pharmamkting.blogspot.ca/ 2012/03/janssen-to-shut-down-psoriasis-360.html (accessed on 8 July 2014).

40. Dominic Tyer. "Janssen to Close Groundbreaking Psoriasis Facebook Page." PMLiVE Digital Intelligence Blog, 21 March 2012. Available online: http://www.pmlive.com/blogs/ digital_intelligence/archive/2012/mar_2012/janssen_closes_psoriasis_360_facebook_page (accessed on 8 July 2014). 
41. Canadian Federation of Nurses Unions. "Direct-to-Consumer Advertising Canadian Federation of Nurses Unions Backgrounder." November 2011. Available online: http://nursesunions.ca/sites/ default/files/2011.backgrounder.dtca_.e.pdf (accessed on 8 July 2014).

42. Ben Comer. "AZ Launches Branded YouTube Channel, Testimonial Site." Medican Marketing \& Media, 6 February 2009. Available online: http://www.mmm-online.com/az-launches-brandedyoutube-channel-testimonial-site/article/127046/ (accessed on 8 July 2014).

43. John Mack. "YouTube Interruptus! Dear WhyInsulin: WHY the Dreadful LANTUS Safety Information Blue Screen and Voiceover?" Pharma Marketing Blog, 27 April 2011. Available online: http://pharmamkting.blogspot.ca/2011/04/youtube-interruptus-dear-whyinsulin-why.html (accessed on 28 April 2014).

44. Adriana Barton. "Big Pharma Wants to 'Friend' You." The Globe and Mail, 24 July 2011. Available online: http://www.theglobeandmail.com/life/health-and-fitness/big-pharma-wants-tofriend-you/article4260322/ (accessed on 8 July 2014).

45. Health Canada. "Health Products Advertising on Physician Websites-Questions \& Answers." 13 July 2011. Available online: http://www.hc-sc.gc.ca/dhp-mps/alt_formats/pdf/advert-publicit/pol/ web-qa-qr-eng.pdf (accessed on 8 July 2014).

46. Alice Tseng. "Pharma and Medical Device Advertising in Social—Worth the Risk?" Blakes, 19 January 2011. Available online: http:/www.blakes.com/English/Resources/Bulletins/Pages/ Details.aspx?BulletinID=1275 (accessed on 8 July 2014).

47. Living Well with Psoriasis. Available online: http://www.livingwellwithpsoriasis.com/home (accessed on 30 April 2014).

48. Megan O’Neill. "What Makes A Video 'Viral'?” SocialTimes, 9 May 2011. Available online: http://socialtimes.com/what-makes-a-video-viral_b61409 (accessed on 8 July 2014).

49. "Sunovion Pharmaceuticals Inc. Announces Partnership with CARE to Help Improve the Health and Lives of Those in Need." Bloomberg, 17 October 2011. Available online: http://www. bloomberg.com/apps/news?pid=newsarchive\&sid=a8v7h3mxZNAk (accessed on 8 July 2014).

50. Start Something with Alesse. Available online: http://www.startsomethingwithalesse.ca/ (accessed on 30 April 2014).

51. Bernard J. Jansen, and Tracy Mullen. "Sponsored Search: An Overview of the Concept, History, and Technology." International Journal of Electronic Business 6 (2008): 114-31.

52. "About Google Ads." Available online: https://support.google.com/ads/answer/1634057?hl= en\&ref_topic $=2971788$ (accessed on 30 April 2014).

53. Maureen Malloy. "What Is the Role of Unbranded Websites in Pharmaceutical Digital Marketing?" Decision Resources Group, 22 September 2010. Available online: http://decisionresourcesgroup.com/News-and-Events/In-The-News/Manhattan-ResearchMaureen-Malloy-DTC-092210 (accessed on 8 July 2014).

54. Health on the Net Foundation. Available online: http://www.hon.ch/HONcode/Patients/ Visitor/visitor.html (accessed on 1 July 2014).

55. Health Canada. "Regulatory Requirements for Advertising_Drugs and Health Products." 23 December 2002. Available online: http://www.hc-sc.gc.ca/dhp-mps/advert-publicit/index-eng.php (accessed on 8 July 2014). 
56. Health Canada. "Guidance Document—Health Canada and Advertising Preclearance Agencies' Roles Related to Health Product Advertising." 3 November 2011. Available online: http://www.hcsc.gc.ca/dhp-mps/advert-publicit/pol/role_apa-pca-eng.php (accessed on 8 July 2014).

57. Tracey Epps. "Regulation of Health Care Professionals." In Canadian Health Law and Policy, 3rd ed. Edited by Nola M. Ries, Tracey Bailey and Timothy Caulfield. Toronto: Butterworths, 2007.

58. Standing Committee on Health. "Opening the Medicine Cabinet: First Report on Health Aspects of Prescription Drugs.” Available online: http://www.parl.gc.ca/HousePublications/Publication. aspx? DocId=1282198\&Language $=$ E\&Mode $=1 \&$ Parl=37\&Ses $=3$ (accessed on 8 July 2014).

59. Women and Health Protection. "CanWest's Charter Challenge on Prescription Drug Advertising: A Citizen's Guide.” 2006. Available online: http://www.whp-apsf.ca/pdf/charter_ challenge_en.pdf (accessed on 8 July 2014).

60. Les Toop, and Dee Richards. "Memorandum by Professor Les Toop and Dr. Lee Richards (Appendix 18 to the Select Committee on Health, Fourth Report)." 22 March 2005. Available online: http://www.publications.parliament.uk/pa/cm200405/cmselect/cmhealth/42/42we21.htm (accessed on 8 July 2014).

61. Health Canada. "Record of Discussions - Canadian Advertising Preclearance Agencies and Health Canada-20 April 2010." Available online http://web.archive.org/web/2013060300 5830/http://www.hc-sc.gc.ca/dhp-mps/advert-publicit/meet-reunion/rod-rdd_2010_04_20eng.php\#a3 (accessed on 8 July 2014).

62. Minister of Health (Canada). "An Act to Amend the Food and Drugs Act." Available online: http://www.parl.gc.ca/Legisinfo/BillDetails.aspx?Mode=1\&billId=6365510\&Language=E (accessed on 8 July 2014).

63. Health Canada. "List of Canadian Advertising Preclearance Agencies." 8 December 2006. Available online: http://www.hc-sc.gc.ca/dhp-mps/advert-publicit/preclear-preapprob/pcaapa_list-eng.php (accessed on 8 July 2014).

64. Baker-Blais. "DTC Regulations 101." Available online: http://www.bakerblais.com/ DTCregulations.html (accessed on 8 July 2014).

65. Catherine Regis. "Direct-to-Consumer Advertising for Prescription Drugs in Canada: Beyond Good or Evil." Health Law Review 14 (2005): 28-33.

66. Canada's Research-Based Pharmaceutical Companies. "2012 Code of Ethical Practices." Available online: http://www.canadapharma.org/CMFiles/Commitment_to_Ethics/WithHealth CareProfessionals/Code_of_Ethical_Practices/2012_CodeofEthicalPractices_ENFinal.pdf (accessed on 8 July 2014).

67. Roy J. Romanow. "Building on Values the Future of Health Care in Canada. Commission on the Future of Health Care in Canada." Available online: http://publications.gc.ca/collections/ Collection/CP32-85-2002E.pdf (accessed on 8 July 2014).

68. Shannon Gibson. "Direct-to-consumer Advertising in the Digital Age: The Impact of the Internet and Social Media in the Promotion of Prescription Drugs in Canada." LLM thesis, University of Toronto, Toronto, Canada, 2012. Available online: http://hdl.handle.net/1807/33218 (accessed on 8 July 2014).

(C) 2014 by the author; licensee MDPI, Basel, Switzerland. This article is an open access article distributed under the terms and conditions of the Creative Commons Attribution license (http://creativecommons.org/licenses/by/3.0/). 